\title{
OPTIMIZATION OF EXOPOLYSACCHARIDES PRODUCTION FROM A NOVEL STRAIN OF GANODERMA LUCIDUM CAU5501 IN SUBMERGED CULTURE
}

\author{
Baojing Yuan, Xiaoyan Chi, Rijun Zhang*
}

Laboratory of Feed Biotechnology, State Key Lab. of Animal Nutrition, College of Animal Science \& Technology, China Agricultural University, No.2 Yuanmingyuan West Road, Haidian District, Beijing 100193, China.

Submitted: March 26, 2011; Returned to authors for corrections: April 09, 2011; Approved: January 16, 2012.

\begin{abstract}
This study aimed at optimizing the medium of a new Ganoderma lucidum strain CAU5501 to enhance the yield of exopolysaccharides (EPS) and mycelial growth. Firstly, the suitable level of glucose, magnesium, phosphate and $\mathrm{C} / \mathrm{N}$ ratio was determined by single factor experiment. Subsequently, the optimum concentrations of these medium components were investigated using the orthogonal matrix method. The results indicated that the higher levels of EPS were correlated with the level of cell growth when glucose concentration was studied (data no show). The optimum medium for EPS yield was found to be $70 \mathrm{~g} / 1$ glucose, $5 \mathrm{C} / \mathrm{N}$ ratio, $2.5 \mathrm{~g} / 1 \mathrm{KH}_{2} \mathrm{PO}_{4}, 0.75 \mathrm{~g} / 1 \mathrm{MgSO}_{4} \cdot 7 \mathrm{H}_{2} \mathrm{O}$, and for mycelial growth was $50 \mathrm{~g} / 1$ glucose, 5 $\mathrm{C} / \mathrm{N}$ ratio, $1.5 \mathrm{~g} / 1 \mathrm{KH}_{2} \mathrm{PO}_{4}, 0.5 \mathrm{~g} / 1 \mathrm{MgSO}_{4} \cdot 7 \mathrm{H}_{2} \mathrm{O}$. When cultivated in the obtained optimal media in $3 \mathrm{~L}$ shake flask, compared to the basal medium, the EPS yield increased markedly from 1.003 to $1.723 \mathrm{~g} / 1$, and the mycelium formation was also markedly improved from 2.028 to $7.235 \mathrm{~g} / \mathrm{l}$. Results obtained in this study are beneficial to further study for enhancing the production of Ganoderma lucidum polysaccharides in large scale commercialized production.
\end{abstract}

Key word: Optimization; exopolysaccharides; Ganoderma lucidum; orthogonal matrix method; submerged culture

\section{INTRODUCTION}

Over the past decades there has been an increasing attention to the production of polysaccharides from mushrooms due to their various physiological activities $(14,17)$. Ganoderma lucidum, a medicinal fungus called "Lingzhi" in Chinese and "Reishi" in Japanese, has been widely used as a remedy for promotion of health and longevity in the Far East, especially in China, Japan and Korea for centuries. Recent studies on G. lucidum have showed polysaccharides is one of the major sources that are considered to possess many bioactivities, such as anti-tumor (5), immunomodulation (13), antioxidation (16).

Polysaccharides yield extracted from fruiting bodies and mycelia is relatively low and its cost is high. By comparison exopolysaccharides (EPS) have several advantages: the use of harsh extraction steps can be avoided in EPS production, thus lessening product degradation during recovery and reducing

*Corresponding Author. Mailing address: Laboratory of Feed Biotechnology, State Key Lab. of Animal Nutrition, College of Animal Science \& Technology, China Agricultural University.; Tel: +86-10-62731208 Fax: +86-10-87969550.; E-mail: feedbiotech@yahoo.com 
production cost. Viewed as a promising alternative for efficient production, submerged cultivation of G. lucidum has attracted much attention recent years. However, most investigators have focused their efforts mainly on polysaccharides from fruiting bodies and mycelia $(6,9,12)$. Little information is available with respect to the optimal condition for EPS production from G. lucidum.

Until now, in spite of several decades of efforts, the production and productivity of secondary metabolites by cell culture technology is still facing many biological and engineering limitations. One of the major obstacles is the low yield of secondary metabolites (19). G. lucidum CAU5501 (China patent application No. 200510066114.7), a novel strain bred by Chi et al. in this Laboratory, is an excellent strain with steady property, high EPS production and high mycelial growth rate (4). Orthogonal design, one of the important statistical methods, is feasible to investigate the influence of controlled factors in a multivariable system and have been successfully applied to the improvement of culture media for the production of primary and secondary metabolites in the fermentation process (9). In the present study, attempts were made to optimize the formulated suitable media for the production of EPS and mycelial biomass by G. lucidum CAU5501 in shake flasks using the orthogonal matrix method.

\section{MATERIALS AND METHODS}

\section{Microorganism and media}

The strain of G. lucidum CAU5501 was screened in this laboratory and maintained on potato dextrose agar (PDA) slants. The slants were inoculated and incubated at $30^{\circ} \mathrm{C}$ for 7 days, then stored at $4^{\circ} \mathrm{C}$ for about 1 month. The seed medium that was also used as the basal medium consisted of $40 \mathrm{~g} / \mathrm{l}$ glucose, $2 \mathrm{~g} / \mathrm{l}$ peptone, $2 \mathrm{~g} / 1 \mathrm{KH}_{2} \mathrm{PO}_{4}, 1 \mathrm{~g} / \mathrm{l} \mathrm{MgSO}_{4} 7 \mathrm{H}_{2} \mathrm{O}$, $40 \mathrm{mg} / 1$ thiamin.

\section{Inoculum preparation and flask culture}

G. lucidum CAU5501 was initially grown on PDA medium in a petridish, and then transferred to the seed culture medium by punching out $5 \mathrm{~mm}$ of the agar plate culture. The seed culture was grown in $250 \mathrm{ml}$ flasks containing $100 \mathrm{ml}$ of basal medium at $30^{\circ} \mathrm{C}$ on a rotary shaker incubator at $150 \mathrm{rpm}$ for 5 days. Shake flask culture experiments were performed in a $250 \mathrm{ml}$ flask containing $100 \mathrm{ml}$ of the media (natural $\mathrm{pH}$ value) after inoculating with $5 \%(\mathrm{v} / \mathrm{v})$ of the seed culture at 150 $\mathrm{rpm}$ in dark at $30^{\circ} \mathrm{C}$ for 4 days. All experiments were performed in triplicate.

\section{Experimental design and data treatment single-factor test}

To find the optimal culture media requirements, the following factors were investigated using the one-factor-at-atime method, namely the glucose, phosphate $\left(\mathrm{PO}_{4}{ }^{3-}\right)$, magnesium: $\left(\mathrm{Mg}^{2+}\right)$ concentrations and carbon-nitrogen ratio in the media.

Concentration of glucose: To determine the optimal carbohydrate concentration in the medium, eight different concentrations $(10,20,30,40,50,60,70$, and $80 \mathrm{~g} / \mathrm{l})$ of glucose were used as the carbon source for production of EPS and mycelium growth by G. lucidum CAU5501.

Carbon-nitrogen ratio: To find out the suitable $\mathrm{C} / \mathrm{N}$ ratio for EPS production and mycelial growth, G. lucidum CAU5501 was cultivated in the media with $40 \mathrm{~g} / 1$ of glucose as carbon source adjusting the ratio of nitrogen source $(\mathrm{C} / \mathrm{N}$ ratio 10,30 , 50, 70 and 90).

Concentration of phosphate: In this work, $\mathrm{KH}_{2} \mathrm{PO}_{4}$ was used as phosphate source to examine the influence of phosphate on EPS production and mycelial growth from $G$. lucidum CAU5501 at different levels (from $1.0 \mathrm{~g} / 1$ to $6.0 \mathrm{~g} / 1$ ) of $\mathrm{KH}_{2} \mathrm{PO}_{4}$ in the midium.

Concentration of magnesium: To find the appropriate $\mathrm{Mg}^{2+}$ concentration for EPS production and mycelia growth of G. lucidum CAU5501 in submerged culture, different levels of $\mathrm{MgSO}_{4} \cdot 7 \mathrm{H}_{2} \mathrm{O}$ ranging from $0.5 \mathrm{~g} / 1$ to $5 \mathrm{~g} / 1$ were tested.

\section{Orthogonal matrix method}

Based on the results of single factor experiments above, 
these media components concentrations for mycelial growth and EPS production were optimized using the orthogonal matrix method. The design of $\mathrm{L}_{9}\left(3^{4}\right)$ orthogonal array was employed for optimizing nutritional components of medium, as noted in Table $1(3,10,18,20)$. The experimental conditions for each experimental group are listed in Table 2 including the experimental results in the last two columns. All experiments were performed in triplicate.

Table 1. L9 $\left(3^{4}\right)$ orthogonal design of optimization of culture medium.

\begin{tabular}{ccccc}
\hline Factor & Variable & Level 1 & Level 2 & Level 3 \\
\hline A & glucose concentration & 50.00 & 60.00 & 70.00 \\
B & C/N ratio & 5 & 10 & 15 \\
C & phosphate concentration & 1.50 & 2.00 & 2.50 \\
D & $\mathrm{Mg}^{2+}$ concentration & 0.50 & 0.75 & 1.00 \\
\hline
\end{tabular}

Table 2. Results of $\mathrm{L}_{9}\left(3^{4}\right)$ orthogonal test of exopolysaccharide production and mycelial growth of G. lucidum CAU5501 in shake flask culture.

\begin{tabular}{ccccccc}
\hline Run & A & B & C & D & EPS production $\left(\mathbf{g ~}^{\mathbf{1}}\right)$ & mycelial biomass $\left.\mathbf{g ~ l}^{\mathbf{1}}\right)$ \\
\hline 1 & 1 & 1 & 1 & 1 & $0.82 \pm 0.08$ & $1.12 \pm 0.06$ \\
2 & 1 & 2 & 2 & 2 & $0.42 \pm 0.08$ & $0.76 \pm 0.27$ \\
3 & 1 & 3 & 3 & 3 & $0.93 \pm 0.10$ & $0.51 \pm 0.12$ \\
4 & 2 & 1 & 2 & 3 & $0.67 \pm 0.18$ & $0.73 \pm 0.13$ \\
5 & 2 & 2 & 3 & 1 & $0.68 \pm 0.02$ & $0.94 \pm 0.09$ \\
6 & 2 & 3 & 1 & 2 & $0.78 \pm 0.11$ & $0.57 \pm 0.08$ \\
7 & 3 & 1 & 3 & 2 & $1.14 \pm 0.02$ & $0.64 \pm 0.28$ \\
8 & 3 & 2 & 1 & 3 & $0.45 \pm 0.18$ & $0.59 \pm 0.20$ \\
9 & 3 & 3 & 2 & 1 & $0.65 \pm 0.07$ & $0.73 \pm 0.02$ \\
\hline
\end{tabular}

Symbols A, B, C and D represent factors of glucose concentration $\left(\mathrm{g}^{-1}\right), \mathrm{C} / \mathrm{N}, \mathrm{KH}_{2} \mathrm{PO}_{4}\left(\mathrm{~g}^{-1}\right)$ and $\mathrm{MgSO}_{4}$, respectively.

Values are means $\pm \mathrm{SD}$ of triple determinations.

\section{Analytical methods}

Exopolysaccharides: Samples from every shake flasks were centrifuged at $4000 \mathrm{rpm}$ for $15 \mathrm{~min}$. The resulting culture filtrate was added to four volumes of absolute ethanol, and left at $4^{\circ} \mathrm{C}$ for $24 \mathrm{hr}$ to precipitate the crude EPS. The precipitated EPS was centrifuged at $10000 \mathrm{rpm}$ for $10 \mathrm{~min}$, with the supernatant discarded, and then the precipitated EPS was dissolved in distilled water, precipitated with alcohol again, by four times. At last, the precipitated EPS was lyophilized and the EPS yield (which was expressed as gram of EPS per litre of culture medium) was measured by a phenol-sulphuric acid method according to Chen et al. (3).

Mycelial growth: The mycelial biomass amount of $G$. lucidum was determined by measuring the dry cell weight (DCW). Fermentation broth collected from each shake flask were filtrated with four layers of gauze and washed three times with distilled water. Then the mycelial pellets were dried at $105^{\circ} \mathrm{C}$ in thermostatic drying chamber until a constant weight was achieved.

\section{RESULTS AND DISCUSSION}

\section{Effect of concentration of glucose}

The concentrations of carbon sources in the media are very important for cell growth and optimal metabolite production (20). As shown in Figure 1A, the more EPS was produced with the increasing of glucose concentration (ranging 
from 10 to $60 \mathrm{~g} / \mathrm{l}$ ) in the media, and the highest yield of EPS $(0.90 \mathrm{~g} / \mathrm{l})$ was obtained when a glucose concentration of $60 \mathrm{~g} / 1$ was used. Similar results were obtained by Lee et al. (12) and Hsieh et al. (6). However, contrary to the previous research by Hsieh et al. (6) who reported that the highest levels of EPS were not correlated with the level of cell growth when $G$. lucidum CCRC 36041 was used for submerged culture, in this study, a noticeable phenomenon was that, the maximum EPS yield and mycelial biomass $(0.72 \mathrm{~g} / \mathrm{l})$ were achieved simultaneously at glucose concentration of $60 \mathrm{~g} / \mathrm{l}$ (Figure 1). It seemed the levels of EPS were correlated with the levels of cell growth (data no show) when G. lucidum CAU5501 was used. These results showed that different strains of Ganoderma lucidun had different metabolic characteristics and there seemed no lag phase between the primary metabolism and the secondary metabolism in G. lucidum CAU5501. This result demonstrated that $G$. lucidum CAU5501 might be a strain which could give consideration to both EPS production and mycelial biomass and the best concentration of glucose was 60 $\mathrm{g} / \mathrm{l}$ in the medium.
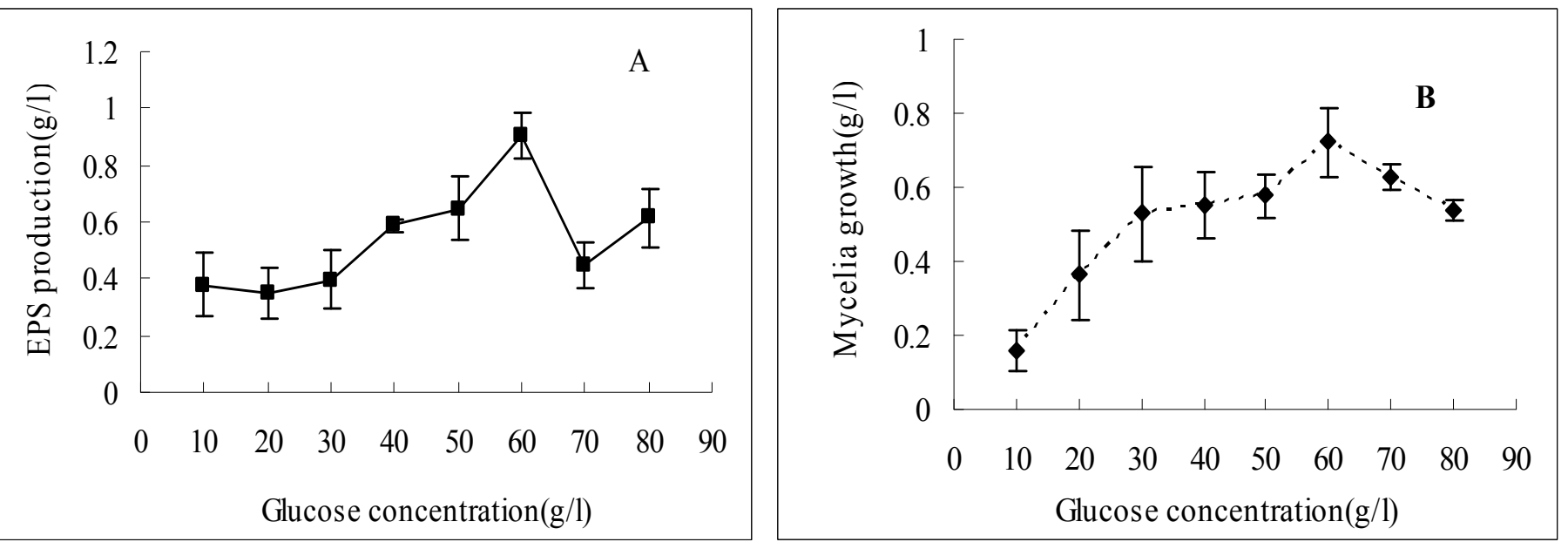

Figure 1. Effect of glucose concentration on exopolysaccharide production (A) and mycelial growth (B) of G. lucidum CAU5501 in shake flask culture.

\section{Effect of carbon to nitrogen ratio ( $\mathrm{C} / \mathrm{N}$ ratio)}

The $\mathrm{C} / \mathrm{N}$ ratio is an important factor affecting the biosynthesis of EPS and mycelial growth in mushroom cultures. The results are shown in Figure 2. The best performance of EPS production was achieved when the ratio of carbon and nitrogen was 10 , and then reduced to the lowest point with $\mathrm{C} / \mathrm{N}$ ratios of 30 . This finding was not in accordance with previous results (at a $\mathrm{C} / \mathrm{N}$ ratio of 25) reported by Babitskaya et al. (1). This variance of EPS production from the same kind of fungus may differ due to strains and their culture conditions. In contrast, the maximum mycelia outgrowth was achieved at $\mathrm{C} / \mathrm{N}$ ratios of 30 , and then decreased with the $\mathrm{C} / \mathrm{N}$ ratios increased from 30 to 90 . These results indicated that $\mathrm{C} / \mathrm{N}$ ratios had effect on both cell growth and EPS accumulation of G. lucidum and a very high $\mathrm{C} / \mathrm{N}$ ratio resulted in a relatively lower yield of mycelial biomass. Moreover, it seemed that good cell growth was not a determining factor for high production yield of EPS, which was in agreement with the previous reports (3). However, the function of $\mathrm{C} / \mathrm{N}$ ratio level with regard to polysaccharides is still unclear and worthy of further study. 

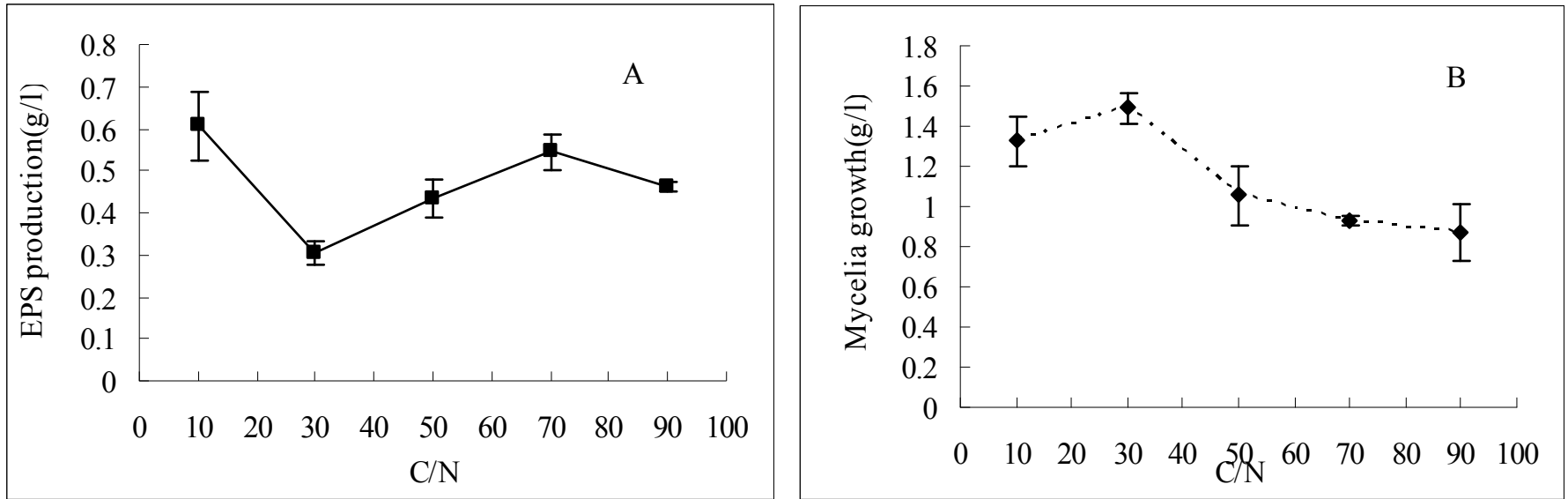

Figure 2. Effect of $\mathrm{C} / \mathrm{N}$ ratio on exopolysaccharide production (A) and mycelial growth (B) of G. lucidum CAU5501 in shake flask culture.

\section{Effect of phosphate $\left(\mathrm{PO}_{4}{ }^{3-}\right)$}

The trace nutrient sources usually affect the rates of biosynthesis of many metabolites. Figure $3 \mathrm{~A}$ showed that phosphate influenced the EPS production of G. lucidum in submerged culture and the maximum EPS production $(0.57 \mathrm{~g} / \mathrm{l})$ was obtained when $\mathrm{KH}_{2} \mathrm{PO}_{4}$ was added to the basal medium at a level of $2.0 \mathrm{~g} / \mathrm{l}$, which was $23.91 \%$ higher than that in fermentation without $\mathrm{KH}_{2} \mathrm{PO}_{4}$ addition. The result suggested that phosphate had promoting effect on EPS accumulation and the proper concentration of was $2.0 \mathrm{~g} / 1 \mathrm{KH}_{2} \mathrm{PO}_{4}$. However, excess phosphate had negative effect on EPS accumulation. In Contrast, $\mathrm{KH}_{2} \mathrm{PO}_{4}$ had slight effect on mycelial biomass, of was difference from the report by Hsieh et al. (6). In addition, the media without phosphate source addition showed certain cell growth and EPS production as showed in Figure 3, the similar phenomenon was observed by other workers (6). The reason for this was that there was some phosphate source contained in the peptone which can satisfy the requirements of cell growth and some requirements for EPS synthesis from $G$. lcidum.
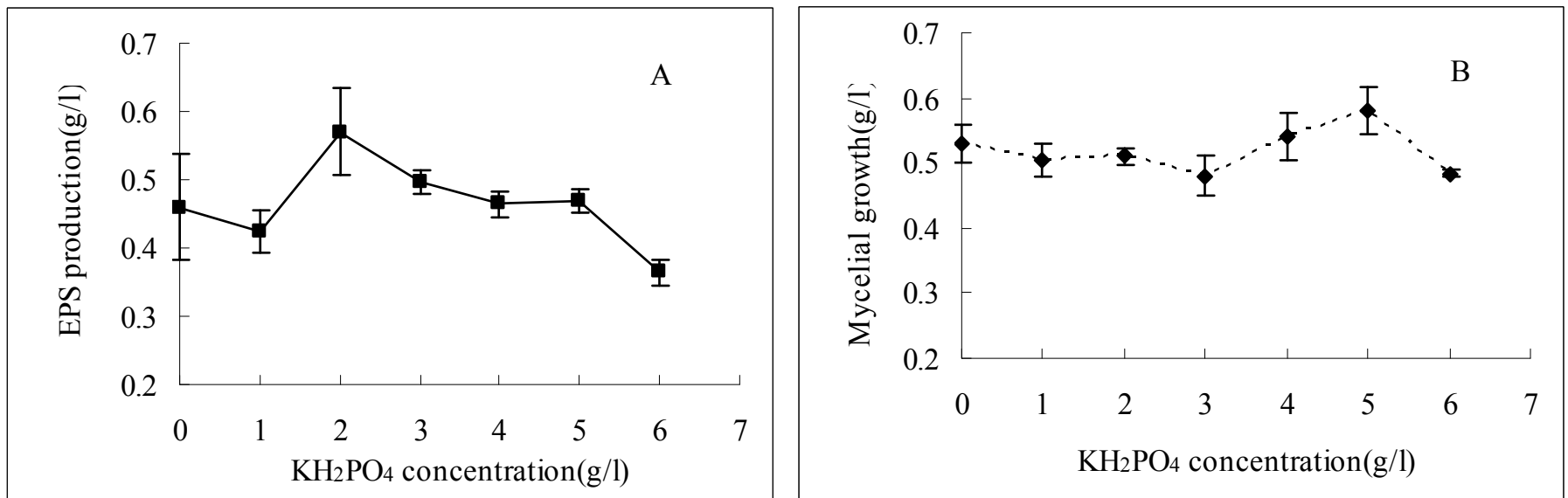

Figure 3. Effect of phosphate concentration on exopolysaccharide production (A) and mycelial growth (B) of G. lucidum CAU5501 in shake flask culture. 


\section{Effect of magnesium ( $\mathrm{Mg}^{2+}$ )}

As showed in Figure 4B. The magnesium supplement showed a significant promotive effect on the mycelial growth of G. lucidum CAU5501. The mycelial production increased from 0.43 to $1.04 \mathrm{~g} / 1$ when magnesium source increased from 0 to $3 \mathrm{~g} / \mathrm{l}$ in the media. The maximum mycelial biomass at $3 \mathrm{~g} / \mathrm{l}$ magnesium sources was about 2.5 times of that at $0 \mathrm{~g} / \mathrm{l}$. In comparison, high concentration of $\mathrm{MgSO}_{4} \cdot 7 \mathrm{H}_{2} \mathrm{O}$ did not demonstrated enhancing effect on the EPS yield. The maximum EPS yield (0.73) was achieved at $1 \mathrm{~g} / 1$ of $\mathrm{MgSO}_{4} \cdot 7 \mathrm{H}_{2} \mathrm{O}$ in the media. The results were in consistent with the previous reports by Hsieh et al. (6) and Kim et al. (10). These findings revealed that an increase of $\mathrm{Mg}^{2+}$ level favored mycelial growth rather than EPS production. It is well known that magnesium is involved in the synthesis of many structural components and stabilizes the plasma membrane $(8,10,11)$. In comparison, thought magnesium also takes part in the synthesis of saccharides metabolism, this role can be replaced by manganese (2). Perhaps this was the reason why magnesium showed more distinct effect on mycelial growth than that of magnesium on EPS production in this work. Another researcher suggested that concentrations of magnesium can change polysaccharides composition rahter than polysaccharide production (6). The function of magnesium with regard to polysaccharides is still unclear, being and worth of further study.
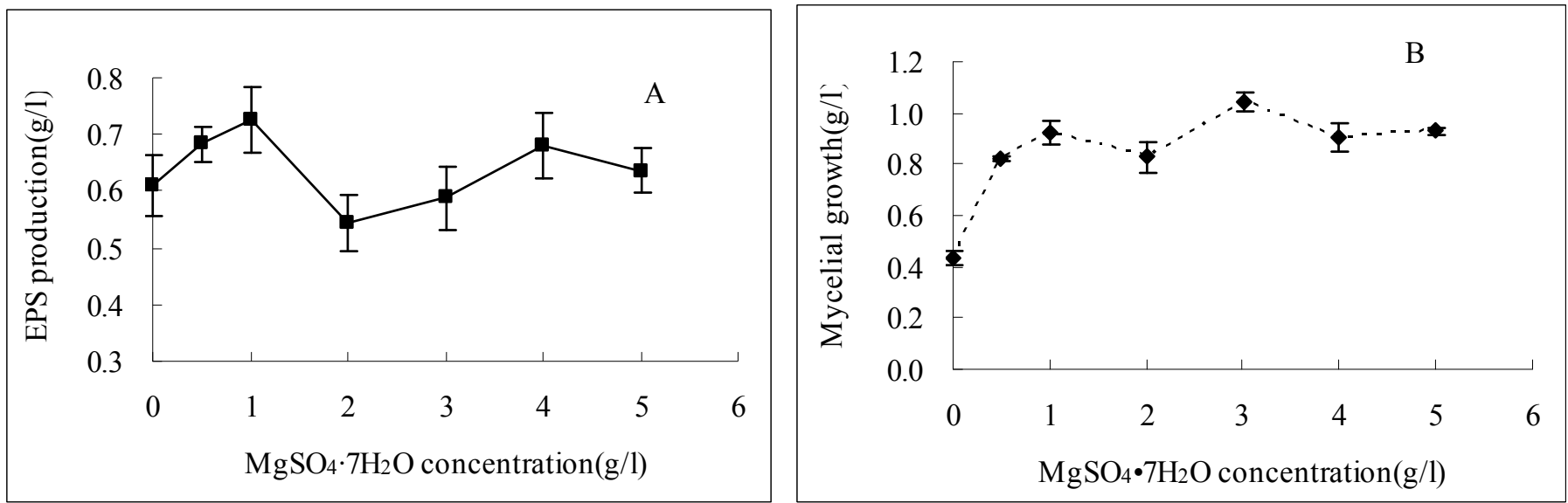

Figure 4. Effect of magnesium concentration on exopolysaccharide production (A) and mycelial growth (B) of G. lucidum CAU5501 in shake flask culture.

\section{Optimization results by the orthogonal matrix method}

Based on the above results achieved, dominated by gaining more EPS the four selected variables (glucose, $\mathrm{C} / \mathrm{N}$ ratios, phosphate and magnesium) for the metabolite production and cell growth were further optimized using an orthogonal layout $\mathrm{L}_{9}\left(3^{4}\right)$.

As shown in Table 2, the highest mean production of EPS by $G$. lucidum CAU5501 was $1.14 \mathrm{~g} / 1$ among 9 experimental groups, where it was the seventh experimental group whose levels of corresponding factors involved $A_{3}, B_{1}, C_{3}$ and $D_{2}$, respectively. Whereas, it was in the first experimental group that mycelia yield reached the maximum value $(1.12 \mathrm{~g} / \mathrm{l})$.

According to the orthogonal method, the effect of those media on EPS production and mycelial growth was analysed and the results were shown in Table 3. Based on the magnitude order of $\mathrm{R}$ value (maximum difference), the order of effects of all factors on EPS production and mycelial growth was estimated respectively. The order of effects of all factors on 
EPS production was $\mathrm{C} / \mathrm{N}$ ratio $>\mathrm{KH}_{2} \mathrm{PO}_{4}>\mathrm{MgSO}_{4}>$ glucose concentration $(\mathrm{B}>\mathrm{C}>\mathrm{D}>\mathrm{A}$ ) while the order of effects of all factors on mycelial growth was $\mathrm{B}>\mathrm{D}>\mathrm{A}>\mathrm{C}$, i.e. $\mathrm{C} / \mathrm{N}$ ratio $>$ $\mathrm{MgSO}_{4}>$ glucose concentration $>\mathrm{KH}_{2} \mathrm{PO}_{4}$. In terms of the maximum $K$ value of each column in Table 3, optimal level of each medium ingredient for EPS production by G. lucidum
CAU5501 was $\mathrm{A}_{3} \mathrm{~B}_{1} \mathrm{C}_{3} \mathrm{D}_{2}$. The levels of corresponding factors included glucose $(70 \mathrm{~g} / \mathrm{l}), \mathrm{C} / \mathrm{N}$ ratio (5), $\mathrm{KH}_{2} \mathrm{PO}_{4}(2.5 \mathrm{~g} / \mathrm{l})$ and $\mathrm{MgSO}_{4} \cdot 7 \mathrm{H}_{2} \mathrm{O}(0.75 \mathrm{~g} / \mathrm{l})\left(\mathrm{A}_{3} \mathrm{~B}_{1} \mathrm{C}_{3} \mathrm{D}_{2}\right)$, respectively. In the same way, the optimal medium for mycelial growth was $A_{1} B_{1} C_{1} D_{1}$, namely glucose concentration $(50 \mathrm{~g} / \mathrm{l}), \mathrm{C} / \mathrm{N}$ ratio $(5), \mathrm{KH}_{2} \mathrm{PO}_{4}$ $(1.5 \mathrm{~g} / \mathrm{l})$ and $\mathrm{MgSO}_{4} \cdot 7 \mathrm{H}_{2} \mathrm{O}(0.5 \mathrm{~g} / \mathrm{l})$.

Table 3. Analysis of $\mathrm{L}_{9}\left(3^{4}\right)$ orthogonal test on exopolysaccharide production and mycelial growth of G. lucidum CAU5501 in shake flask culture.

\begin{tabular}{|c|c|c|c|c|}
\hline & \multicolumn{4}{|c|}{ exopolysaccharide production } \\
\hline & $\mathbf{A}$ & $\mathbf{B}$ & $\mathbf{C}$ & $\mathbf{D}$ \\
\hline$K_{1}$ & $2.17 \pm 0.26$ & $2.63 \pm 0.28$ & $2.05 \pm 0.37$ & $2.16 \pm 0.17$ \\
\hline$K_{2}$ & $2.13 \pm 0.31$ & $1.56 \pm 0.28$ & $1.75 \pm 0.33$ & $2.34 \pm 0.21$ \\
\hline$K_{3}$ & $2.24 \pm 0.27$ & $2.36 \pm 0.28$ & $2.75 \pm 0.14$ & $2.05 \pm 0.46$ \\
\hline$k_{1}$ & $0.72 \pm 0.09$ & $0.88 \pm 0.09$ & $0.68 \pm 0.12$ & $0.72 \pm 0.06$ \\
\hline$k_{2}$ & $0.71 \pm 0.10$ & $0.52 \pm 0.09$ & $0.58 \pm 0.11$ & $0.78 \pm 0.07$ \\
\hline$k_{3}$ & $0.75 \pm 0.09$ & $0.79 \pm 0.09$ & $0.92 \pm 0.05$ & $0.68 \pm 0.15$ \\
\hline$R$ & $0.04 \pm 0.19$ & $0.36 \pm 0.18$ & $0.34 \pm 0.16$ & $0.10 \pm 0.22$ \\
\hline \multirow[t]{3}{*}{ Optimal level } & 3 & 1 & 3 & 2 \\
\hline & \multicolumn{4}{|c|}{ mycelial growth } \\
\hline & $\mathbf{A}$ & $\mathbf{B}$ & $\mathrm{C}$ & $\mathbf{D}$ \\
\hline$K_{l}$ & $2.39 \pm 0.45$ & $2.49 \pm 0.47$ & $2.28 \pm 0.34$ & $2.79 \pm 0.19$ \\
\hline$K_{2}$ & $2.24 \pm 0.30$ & $2.29 \pm 0.56$ & $2.22 \pm 0.42$ & $1.97 \pm 0.63$ \\
\hline$K_{3}$ & $1.96 \pm 0.50$ & $1.81 \pm 0.22$ & $2.09 \pm 0.49$ & $1.83 \pm 0.45$ \\
\hline$k_{1}$ & $0.80 \pm 0.15$ & $0.82 \pm 0.16$ & $0.88 \pm 0.11$ & $0.94 \pm 0.06$ \\
\hline$k_{2}$ & $0.75 \pm 0.10$ & $0.93 \pm 0.19$ & $0.78 \pm 0.14$ & $0.69 \pm 0.21$ \\
\hline$k_{3}$ & $0.65 \pm 0.17$ & $0.60 \pm 0.07$ & $0.70 \pm 0.16$ & $0.73 \pm 0.15$ \\
\hline$R$ & $0.15 \pm 0.32$ & $0.68 \pm 0.69$ & $0.19 \pm 0.83$ & $0.25 \pm 0.96$ \\
\hline Optimal level & 1 & 1 & 1 & 1 \\
\hline
\end{tabular}

\section{Fermentation results in 3-L shake flask}

To verify the credibility of experiment results, G. lucidum CAU5501 was cultured in optimized media for EPS production or mycelial growth in 3-litre shake flask (work volume 1.21 ). The result suggests that EPS production reached $1.723 \mathrm{~g} / 1$ in optimal medium, which was $70 \%$ higher than that in the basal medium(1.003 g/1), and the mycelia outgrowth (7.235 g/l) was about 3.6 times as much as that in the basal medium(2.028 g/l).
But the mycelia growth were no evident variance between the optimal medium for EPS (7.016 g/l) and the optimized medium for mycelial biomass. Consideration to EPS yield and mycelia output, the optimal combination of $\mathrm{A}_{3} \mathrm{~B}_{1} \mathrm{C}_{3} \mathrm{D}_{2}$ was better.

The results obtained in this work suggested the more EPS was produced with the increasing of glucose level (ranging from 10 to $60 \mathrm{~g} / \mathrm{l}$ ) in the media, and the higher levels of EPS were correlated with the levels of cell growth; magnesium had 
distinct influence on mycelia output, but had insignificant impact on EPS yield. The optimal media were found to be composed of (g/l): glucose $70, \mathrm{C} / \mathrm{N}$ ratio 5, $\mathrm{KH}_{2} \mathrm{PO}_{4} 2.5$ and $\mathrm{MgSO}_{4} \cdot 7 \mathrm{H}_{2} \mathrm{O} 0.75$ for EPS production, and for mycelia the optimal media consisted of: glucose $50, \mathrm{C} / \mathrm{N}$ ratio $5, \mathrm{KH}_{2} \mathrm{PO}_{4}$ 1.5 and $\mathrm{MgSO}_{4} \cdot 7 \mathrm{H}_{2} \mathrm{O}$ 0.5. With the comprehensive assessment of the EPS yield and mycelia output, the combination of $\mathrm{A}_{3} \mathrm{~B}_{1} \mathrm{C}_{3} \mathrm{D}_{2}$ was the best medium for $G$. lucidum CAU5501 culture in shake flask.

\section{ACKNOWLEDGEMENTS}

This work was Supported by State Key Laboratory of Animal Nutrition. (No. 2004DA1251840810).

\section{REFERENCES}

1. Babitskaya, V.G.; Shcherba, V.V.; Pushkova, T.A.; Smirnov, D.A. (2005). Polysaccharides of Ganoderma lucidum: factors affecting their production. Appl. Biochem. Microbiol., 41,169-173.

2. Bock, C.W.; Katz, A.K.; Markham, G.D.; Glusker, J.P. (1999). Manganese as a replacement for magnesium and zinc: functional comparison of the divalent ions. J. Am. Chem. Soc., 121, 7360-7372.

3. Chen, W.; Zhao, Z.; Chen, S.F.; Li, Y.Q.; (2008). Optimization for the production of exopolysaccharide from Fomes fomentarius in submerged culture and its antitumor effect in vitro. Bioresource Technol., 99 (8), 3187-3194.

4. Chi, Xy.; Wang, Z.; Zhang, R.j.; (2006). Breeding of Ganoderma lucidum polysaccharide-peptide complex(GPSPc) high yield striain by UV Induced protoplast mutagenesis and substituted effect of GPSPc on antibiotics in broiler chicken. J. Agric. Biotechnol., 14 (4), 51 1-516.

5. Hsiao, W.L.; Li, Y.Q.; Lee, T.L.; Li, N.; You, M.M.; Chang, S.T.; (2004). Medicinal mushroom extracts inhibit ras-induced cell transformation and the inhibitory effect requires the presence of normal cells. Carcinogenesis, 25(7), 1177-83.

6. Hsieh, C.; Tseng, M.H.; Liu, C.J. (2006). Production of polysaccharides from Ganoderma lucidum (CCRC. 36041) under limitations of nutrients. Enzyme Microb. Technol., 38, 109-117.

7. Hua, K.F.; Hsu, H.Y.; Chao, L.K.; Chen, S.T.; Yang, W.B.; Hsu, J.; Wong, C.H. (2007). Ganoderma Lucidum polysaccharides enhance CD14 endocytosis of LPS and promote TLR4 signal transduction of cytokine expression. J. Cell Physiol., 212, 537-550.

8. Hurwitz, C.; Rosano, C.L. (1967). The intracellular concentration of bound and unbound magnesium ions in Escherichia coli. J. Biol. Chem., 242, 3719-3722.
9. Kim, H.M.; Paik, S.Y.; Ra, K.S.; Koo, K,B.; Yun, J.W.; Choi, J.W. (2006). Enhanced production of exopolysaccharides by fed-batch culture of Ganoderma resinaceum DG-6556. J. Microbiol., 44 (2), 233-242.

10. Kim, H.O.; Lim, J.M.; Joo, J.H.; Kim, S.W.; Hwang, H.J.; Choi, J.W.; Yun, J.W. (2005). Optimization of submerged culture condition for the production of mycelial biomass and exopolysaccharides by Agrocybe cylindracea. Bioresource Technol., 96, 1175-1182.

11. Klein, D.J.; Moore, P.J.; Steitz, T.A. (2004). The contribution of metal ions to the structural stability of the large ribosomal subunit. $R N A, 10$, 1366-1379.

12. Lee, W.Y.; Park, Y.; Ahn, J.K.; Ka, K.H.; Park, S.Y. (2007). Factors influencing the production of endopolysaccharide and exopolysaccharide from Ganoderma applanatum. Enzyme Microb. Technol., 40(2), 249. 254.

13. Mojadadi, S.; Ebtekar, M.; Hassan, Z.M. (2006). Immunomodulatory effects of Ganoderma lucidum (W. Curt.:Fr.) P. Karst. (aphyllophoromycetideae) on $\mathrm{CD} 4+/ \mathrm{CD} 8+$ tumor infiltrating lymphocytes in breast-cancer-bearing mice. Int. J. Med. Mushrooms., 4, 315-320.

14. Pinto, M.R.; Barreto-Bergter, E., Taborda, C.P. (2008). Glycoconjugates and polysaccharides of fungal cell wall and activation of immune system. Braz. J. Microbiol., 39, 195-208.

15. Rubel, R.; Santa, H.S.D.; Fernandes, L.C.; Filho, J.H.C.L.; Figueiredo, B.C.; Di Bernardi, R.; Moreno, A,N.; Leifa, F.; Soccol, C.R. (2008). High immunomodulatory and preventive effects against sarcoma 180 in mice fed with Ling Zhi or Reishi mushroom Ganoderma lucidum (W. Curt.: Fr.) P. Karst. (Aphyllophoromycetideae) mycelium. Int. J. Med. Mushrooms., 10, 37-48.

16. Sudheesh, N.P.; Ajith, T.A.; Janardhanan, K.K. (2009). Ganoderma lucidum (Fr.) P. Karst enhances activities of heart mitochondrial enzymes and respiratory chain complexes in the aged rat. Biogerontology, 10(5), 627-36.

17. Vieira, G.R.T.; Liebl, M.; Benathar, L.; Tavares, B.; Paulert, R.; Júnior, A.S. (2008). Submerged culture conditions for the production of mycelial biomass and antimicrobial metabolites by Polyporus tricholoma Mont. Braz. J. Microbiol., 39(.3), 561-568.

18. Zhang, Z.C.; Li, Y.; Zhang, K.C. (2007). Application of statistical analysis for the optimization of mycelia and polysaccharide production by Tremella aurantialba. Food Tech. Biotech., 45, 45-50.

19. Zhu, L.W.; Zhong, J.J.; Tang, Y.J. (2008). Significance of fungal elicitors on the production of Ganoderma polysaccharides and ganoderic acid by submerged fermentation of medicinal mushroom Ganoderma lucidum. Process Biochem., 43,1359-1370.

20. Zou, X. (2005). Optimization of nutritional factors for exopolysaccharide production by submerged cultivation of the medicinal mushroom Oudemansiella radicata. World J. Microbiol. Biotechnol., 21, 12671271. 